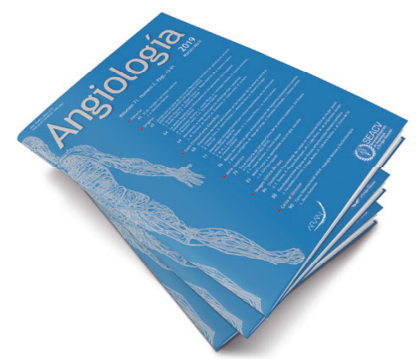

\title{
Nota Histórica
}

\section{René Leriche y su aportación a la cirugía vascular}

René Leriche and his contribution to vascular surgery

José A. González-Fajardo

Servicio de Angiología y Cirugía Vascular. Hospital Universitario 12 de Octubre. Madrid

\begin{abstract}
"Todo cirujano lleva en su interior un pequeño cementerio al que acude a rezar de vez en cuando, un lugar lleno de amarguras y pesar, en el que debe buscar explicación a sus fracasos".
\end{abstract}

René Leriche. La filosofía de la cirugía, 1951

René Leriche es uno de los grandes pioneros de la cirugía vascular, pero también un humanista y exponente de lo que será la nueva cirugía científica a principios del siglo xx $(1,2)$.

Nacido en 1879 en Roanne (Francia), René Henri Marie Leriche se inclinó inicialmente hacia la carrera militar, pero finalmente decidió continuar el camino de su familia en medicina y cirugía. Estudió en la Universidad de Lyon, donde conoció a Alexis Carrel antes de que este se marchara a Montreal (Canadá). De hecho, Carrel fue jefe de residentes y durante un periodo compartió con él las vivencias médicas de ese periodo. Ambos tuvieron como maestro a Mathieu Jaboulais, quien les influyó en el interés por las suturas y los vasos sanguíneos. Se licenció en 1906 con una tesis sobre la técnica quirúrgica en el cáncer de estómago e hizo su formación quirúrgica con Antonin Poncet en Lyon.

Por sugerencia de su colega Alexis Carrel, viajó a Estados Unidos. Allí ve el diseño y la organización del laboratorio de investigación de su amigo en Chicago y visita a varios renombrados cirujanos, como Harvey Cushing en Boston, Simon Flexner en la Fundación Rockefeller, promotor de una "cirugía cuidadosa", y William Haldsted en Baltimore, quien le impresionó profundamente "por su práctica clínica, sus conceptos innovadores de rigurosa asepsia y antisepsia, una mente quirúrgica anatómica-fisiológica, una hemostasia perfecta y un trato exquisito de los tejidos" (3).

A pesar de la diferencia de edad, René Leriche cambió su manera de ver la cirugía y mantuvo con él una relación de amistad hasta la muerte del cirujano americano. Le proponen que se quede en Norteamérica, pero el estallido de la I Guerra Mundial hará que desista de esos sueños. Este gran conflicto representó para él un escenario perfecto para adquirir un gran adiestramiento quirúrgico y un contacto directo con las lesiones traumáticas y sus secuelas; entre ellas, el dolor que se perpetuaba en heridas y muñones amputados ("solo hay un tipo de dolor que es fácil de soportar: el dolor de otros"). De esa época le viene su interés por el sistema nervioso simpático y su papel en el mantenimiento del dolor (distrofia simpático-refleja o causalgia), lo que le llevará a proponer la simpatectomía periarterial como un modo de mitigar las molestias. De forma secundaria, como buen observador, advirtió el calentamiento de los miembros (1-3).
Recibido: 18/2/2019 • Aceptado: 25/3/2019

González-Fajardo JA. René Leriche y su aportación a la cirugía vascular. Angiología 2019;71(2):81-83. DOI: http://dx.doi.org/10.20960/angiologia.00042
Correspondencia:

José A. González-Fajardo. Servicio de Angiología y Cirugía Vascular. Hospital Universitario 12 de Octubre. Avda. de Córdoba, s/n. 28041 Madrid e-mail: gonzalezfajardo@gmail.com 
Después de la Gran Guerra vuelve a Lyon como cirujano y publica sus primeros escritos sobre la patofisiología del hueso (Tratamiento de las fracturas de guerra) y el dolor. En 1923, hace sus primeras observaciones sobre la enfermedad oclusiva aortoilíaca y en 1924 consigue la promoción y oportunidad como profesor de Cirugía en Estrasburgo. Durante este periodo su clínica se convierte en un sitio de peregrinaje para cirujanos de todo el mundo, entre ellos Michael DeBakey, Joao Cid dos Santos o franceses como Jean Kunlin o René Fontaine. DeBakey describe su experiencia: "El espíritu de camaradería entre sus asistentes, residentes e internos, la permanente atmósfera de entusiasmo en la clínica, la admiración y simpatía de sus pacientes, claramente ejemplifican la personalidad y características admirables de este gran hombre" (4).

Tres años más tarde, en 1927, fue nombrado Socio de Honor del Real Colegio de Cirujanos de Inglaterra. En esa época, describe la asociación de la oclusión aortoilíaca con la ausencia de pulsos femorales, la claudicación intermitente y la impotencia (conocida hoy día como Síndrome de Leriche) (1-3), establece con Fontaine los estadios clínicos de la arteriopatía crónica $(5,6)$ y sugiere que la resección del segmento arterial obliterado sería el tratamiento ideal, pero no existía por entonces ni la heparina ni la arteriografía diagnóstica que delimitara la lesión, lo que contribuyó al desarrollo y promoción de la simpatectomía y el estudio del sistema simpático, un campo en el que convergía el dolor y la enfermedad arterial periférica (3).

Pero, además, era un hombre de ideas, excepcionalmente creativo, cuya principal característica era su capacidad de análisis y su extrema amabilidad. Leriche fue un carismático profesor y un buen orador en público. Hablaba de que la responsabilidad de un profesor era atender el cuidado de sus pacientes, la docencia de los estudiantes y el desarrollo de la investigación. Su estilo pedagógico era socrático, lo que le atrajo numerosos estudiantes y visitantes. "Tan agudo era su poder de observación e inspiración, que eran muy pocos cirujanos de su generación los que se preguntaba siempre ¿por qué?" (7).

De la misma forma que presentó y divulgó a la Sociedad Médica Francesa la tromboendarterectomía que Cid Dos Santos había realizado con éxito en Portugal (1947) (8), Leriche observó los prometedores resultados del bypass femoropoplíteo de vena safena que su pupilo Jean Kunlin había realizado en un hombre abocado a la amputación (1948) (9). Tanto una como otra cirugía arterial directa se beneficiaron del advenimiento de la heparina y de la arteriografía que Reynaldo Dos Santos había desarrollado en Lisboa y que aprendieron de su hijo. Estos hechos hablan a favor de un hombre a quien su equipo veneraba. Estos tres procedimientos (simpatectomía, tromboendarterectomía y bypass) fueron durante décadas los pilares de la cirugía vascular universal.

En 1936 se traslada a París. Sucede a Charles NicoIle en la universidad y ocupa la Cátedra de Medicina Experimental como sucesor de Magendie, Claude Bernard y Brown Sequard, lo que le permitió continuar con sus investigaciones y conceptualizar sus teorías fisiopatológicas, pero se fue alejando de la práctica quirúrgica. Sus estudios van desde los cambios vasomotores, humorales y hematológicos producidos por la cirugía (fue el primero en dar a estas modificaciones un nombre, la maladie postoperatoire) a la patofisiología del hueso y las fracturas. Muchas de sus teorías neuroendocrinas no sostuvieron el paso del tiempo, pero lo realmente importante fue cambiar la mentalidad quirúrgica de la época, que pasó de ser anátomo-clínica, en la que la rapidez era una virtud, a una visión anatómico-fisiológica y extraordinariamente delicada y meticulosa (1-3).

La II Guerra Mundial supuso un auténtico desastre en su carrera profesional, aunque fue elegido miembro de la Academia de Ciencias y de la Academia Nacional de Medicina. El título de su autobiografía póstuma, Souvenirs de ma vie mort (Recuerdos de mi vida muerta), publicada en 1956, tal vez refleje esa pesadumbre. Recogido y retirado en Cassis, un pequeño pueblo del sur de Francia, murió el 28 de diciembre de 1955, a los 76 años.

Leriche fue un cirujano muy ingenioso y cualificado, y también un francés que amó la cocina y los buenos vinos y un ávido lector que apreció las obras de arte. De hecho, uno de sus pacientes fue Henri Matisse, quien le hizo un retrato para uno de sus libros. Como anécdota curiosa, referenciada por Martínez Pérez M. (10), Leriche visitó Barcelona para hacer la primera simpatectomía española (1946). Brevemente, el cuñado del insigne traumatólogo Josep Trueta 
adolecía de una isquemia arterial crónica, y este, que estaba exiliado en Oxford, lo comentó con su anestesista, el prestigioso Dr. Robert Macintosh (precursor y creador de la anestesia moderna). Trueta, que tenía conocimiento y amistad con Leriche por sus trabajos óseos, le transmitió este pesar. Ellos, anestesista y cirujano, se desplazaron a Barcelona y realizaron la simpatectomía lumbar en la clínica Corachán con el Dr. Rodríguez Arias. Disfrutaron de la buena comida y de la hospitalidad española, lo que les hizo repetir un mes más tarde para hacer una simpatectomía del lado contralateral. Sirva este ejemplo de altruista amistad para ilustrar el carácter humano y cercano de este hombre que fue apreciado por discípulos, compañeros y enfermos a lo largo de su vida.

Fue un prolífico autor, con 1400 publicaciones sobre todos los campos de la cirugía. En vida recibió numerosas distinciones y fue doctor honoris causa por 15 universidades (entre ellas Harvard), y al final de sus días vio el desarrollo de la cirugía restaurativa desarrollada por sus pupilos. "Hizo posibles horizontes que no eran milagros" al estimular la reflexión y el razonamiento de quienes fueron sus discípulos (1). Aunque no fue el padre de la cirugía vascular, fue el padre espiritual de muchas de las ideas que contribuyeron a su desarrollo. Jean Kunlin escribió de él: "Fue durante 30 años la cabeza de una escuela excepcional de cirugía. En él se combinaba una imaginación muy fértil con una vasta experiencia clínica. La generación de médicos que lo conocieron todavía lo recuerdan por sus lecciones" (1).

Pero Leriche fue, además, un gran pensador. En sus últimos años, ya enfermo y retirado, recoge en su Filosofía de la cirugía muchas sentencias y pensamientos que divulgó durante su época académica y que siguen siendo válidos actualmente $(2,3)$ :

"Es posible capacitarse para ser cirujano después de un tiempo de razonable entrenamiento, adquiriendo así las habilidades necesarias. Sin embargo, llevar a cabo una cirugía en el modo adecuado y en el momento oportuno, sabiendo si es necesaria en ese momento o si puede ser evitada, evaluar las posibilidades de éxito o fracaso en esas condicio- nes, reconocer la evolución que puede esperarse y los cambios in situ del plan quirúrgico que pueden ser necesarios y los medios para obtener el mejor resultado... Esos son los aspectos más difíciles del arte de la cirugía y los elementos que constituyen su ciencia".

Tal vez el tributo que Sir James Learmouth (3) escribió a su muerte, recordando su visita a la Universidad de Edimburgo como profesor visitante de Cirugía y su conferencia sea ilustrativo de esta gran figura: "... desde el primer momento que inició su lectura, deliberadamente en francés, se ganó el corazón de los estudiantes escoceses. Ellos escucharon cautivados y cuando dejó el anfiteatro ellos aplaudieron entusiásticamente. Un joven marchó entonces allí tocando con la gaita una melodía triunfal escocesa. En mi vida había visto u oído algo igual. ¿La razón de este acogimiento? Estos jóvenes conocían que era un gran cirujano de reconocido prestigio, pero esto no fue todo. Ellos vieron cómo compartía con humildad y devoción su servicio hacia ellos".

\section{BIBLIOGRAFÍA}

1. Kieny R. René Leriche and his work as time goes by. Ann Vasc Surg 1990;4:105-11.

2. Davies MK, Hollman A. René Henri Marie Leriche (18791955). Heart 1997;77:98.

3. Jarrett F. René Leriche (1879-1955): father of vascular surgery. Surgery 1979;86:736-41.

4. DeBakey M, Saldarriaga A. The clinic of Professor René Leriche. New Orleans. Med Surg J 1938;90:606.

5. Fontaine R. Quelques contributions à I'histoire moderne de la chirurgie vasculaire. Bol Acad Nac Cienc 1972;49:265.

6. González-Fajardo JA. René Fontaine. Angiología 2014;66:146-8.

7. Mallet-Guy P. Hommage à René Leriche par ses élèves. París: Ed. Masson; 1956.

8. Dos Santos JC. Sur la desobstruction des thromboses arterielles anciennes. Mem Acad Chir 1947;73:409.

9. Kunlin J. Le traitment de l'arterite obliterante par la greffe veineuse. Arch Mal Coeur 1949;42:371.

10. Martínez-Pérez M, Franco-Grande A, Unzueta-Merino MC, Hervás-Puyal C, Villar-Landeira. La simpatectomía española de René Leriche. Angiología 2005;57:451-6. 